\title{
Satisfaction of the Clinical Teachers on Standardized Residency Training Program (SRTP) in China
}

\author{
Boyan Chen \\ Zhejiang University \\ Xiaoyuan Jin \\ Zhejiang University \\ Jie Zhou \\ Zhejiang University \\ Ying Chen \\ Zhejiang University \\ Hongmei Wang ( $\square$ rosa@zju.edu.cn ) \\ Zhejiang University
}

\section{Research Article}

Keywords: residents, clinical teachers, Standardized Residency Training Program (SRTP), cognitive job satisfaction

Posted Date: November 15th, 2021

DOI: https://doi.org/10.21203/rs.3.rs-1048773/v1

License: @ (1) This work is licensed under a Creative Commons Attribution 4.0 International License. Read Full License 


\section{Abstract}

Background: Standardized Residency Training Program (SRTP) is a significant initiative to deepen health systems and medical education in developed countries like China. Despite prompting the SRTP nationwide and implementing it with various improvements, Chinese continuous medical education is still in its infancy. Compared with the residents, little is known about clinical teachers under SRTP in China; but clinical teachers effectively determine the training quality as a critical disseminator of knowledge, skills, and values in medical practice. Thus, the study aims to analyze critical factors affecting their cognitive job satisfaction and provide continuous improvements for SRTP.

Methods: From December 1, 2018, to May 31, 2019, we conducted a self-design questionnaire from 13 SRTPs (including both training bases and professional bases) in Shaoxing city to evaluate participants' satisfaction. Altogether, 574 clinical teachers responded to the survey with generally high overall satisfaction. We adopted Chi-square Test and Fisher's Exact Test to evaluate the single impact factors affecting the satisfaction of clinical teachers. The multiple factors analysis applied the Logistic Regression model.

Results: The male clinical teachers had significant differences in satisfaction of teaching content (OR: 0.675, [95\%Cl: 0.477 0.953]), conflicts between study and work (OR: 0.542, [95\% Cl: 0.371 0.791]), the attention of leaders (OR: $0.403,[95 \% \mathrm{Cl}: 0.252 \sim 0.645]$ ) and subsidies of teachers (OR: 0.527, [95\%Cl: 0.347 0.805]). Compared with internal medicine, clinical teachers from Surgery (OR: 2.396, [95\% Cl: 1.365-4.206]) and other departments (OR: 2.409, [95\%Cl: 1.406-4.129]) were more satisfied when considered residents have high motivation on training. Besides, compared with attending physician, deputy chief physician (OR: $0.493,[95 \%$ Cl: $0.310-0.783]$ ) and chief physician (OR: 0.683, [95\% Cl: 0.471-0.991]) more disagreed that residents' wage is good enough.

Conclusion: Clinical teachers widely recognize the SRTP. However, teachers' satisfaction varied due to different genders, working clinical departments, and professional titles. The study also discussed possible reasons and strategy implications behind these findings, which combined unique Chinese society characteristics. Further, we believe the analysis and interpretations remind us of the applications of Western medical education methods, and theories also should consider the unique socio-cultural challenges.

\section{Background}

The international medical community recognizes the residency training is crucial for building a high-quality medical team, improving the overall medical services level, and ensuring the quality of care. ${ }^{1.2}$ In Europe and the United States, residency training has been standardized and formed as a relatively complete management system after hundreds of years of development; even already built complected training system to train medical doctors at all levels, including entry-level, postgraduate, and continuing medical education. ${ }^{3-6}$ Drawing from world experience, China also focused on developing residency training programs in the past few years.

\section{Standardized Residency Training Program (SRTP)}

Since 2014, the National Health and Family Planning Commission (NHFPC) in China has implemented Standardized Residency Training Program (SRTP) to require all graduated medical students to complete a 3-year training before starting their careers. ${ }^{7-9}$ Being different from the American type of residency program, which was launched in some University affiliated hospitals, SRTP implemented nationwide into both training bases (medical and health institutions, e.g., hospitals) and professional bases (professional clinical departments). ${ }^{7,10}$ In detail, the training bases chose to be professional enough without any criticism of medical safety incidents in the past 3 years, and train residents' basic clinical practices from rotating the significant departments of two-level disciplines. The professional bases set with rigorous requirements on faculty conditions (e.g., the internal department has to set the total number of beds $\geq 200$, the bed utilization rate of $\geq 85 \%$, the annual number of inpatient admissions $\geq 3800$, the annual outpatient volume $\geq 100,000$, and the annual emergency volume of $\geq 10,000$ ), to train residents' clinical skills in a particular department of three-level disciplines. $7,8,10-12$

Until 2020, the promotion of SRTP increased the cumulated number of residents nationwide to 332,000 (recoded as 480,000 if included the postgraduate specialties); 45,000 residents trained as general practitioners, and 20,000 residents worked as pediatrics after completed the training. ${ }^{9}$ Further, as a significant initiative to deepen health systems and medical education, ${ }^{1}$ SRTP already trained qualified clinicians with various improvements from improving teaching quality, providing comfortable studying settings, and 
enlarging clinical cases as teaching contents. According to the reports from National Medical Examination Center (NMEC), the pass rates of residents who participated in the SRTP in 2018 for the first time in the clinical practice qualification examination were $20 \%$ higher than those who did not receive pieces of training from SRTP. ${ }^{15}$ From 2017 to 2018, a total of 120,000 residents have successfully passed the complete examination and obtained training certificates. ${ }^{15}$

\section{Clinical Teachers}

Clinical teaching is the cornerstone for medical students' professional development; thus, clinical teachers effectively determine the training quality as a critical disseminator of knowledge, skills, and values in medical practice. SRTP involves clinical teachers with rigorous certification-only the physician with at least three years of experience as an attending physician or above can work as a clinical teacher. 10 The faculty training requires teachers to receive uniform qualifications, to be familiar with the standardized training regulations. ${ }^{10,13,14}$ Further, the SRTP limits the number of supervised residents from each clinical teacher who cannot train more than three simultaneously. 9,10

Despite prompting the SRTP nationwide and implementing it with various improvements, Chinese continuous medical education is still in its infancy. In the developed stage, the training to become resident doctors depends on the hospitals employed, leading to differential medical levels across regions. Moreover, the imbalance and inadequacy in its development have conflicted with increasing medical demand. ${ }^{16}$ Thus, the SRTP has increasingly attracted more attention from all walks of life, primarily academic studies. In the previous studies, many researchers sought to understand residents' perceptions about SRTP and observe their mental health. ${ }^{16-19}$ Moreover, many studies are mature to test residents' satisfaction and collect their evaluations regarding training organizations ${ }^{20,21,16}$-training from the SRTP is beneficial. Approximately one-third of learning in the clinical setting comes from clinical teachers. ${ }^{1}$

However, compared with our knowledge of residents, little is known about clinical teachers under SRTP in China. The limited studies discussed the clinical teachers have close relationships with their resident students to provide optimal teaching approaches, contribute a lot to the residents' studies, and even spend up to one-fourth of time supervising, instructing, and evaluating students. ${ }^{1,3}$ The positive teaching approach and perceived high-quality education for residents are undoubtedly associated with high overall satisfaction with SRTP. ${ }^{20}$ Herein, this study aimed to investigate the status quo and affecting factors of clinical teachers' cognitive job satisfaction and provide proper advice and measures for the sustainable development of standardized training. Also, we believe in standing on another perspective of the clinical teachers. Analyzing their satisfaction with the SRTP is beneficial for recommending strategies for the national resident training.

\section{Methods}

Using a simple random sampling method, we set out to evaluate cognitive job satisfaction amongst clinical teachers of 13 residency standardization bases in Shaoxing, Zhejiang Province. The evaluated results were collected by asking all of the involved participants to answer a self-designed survey.

\section{Sampling and participants}

From December 1, 2018, to May 31, 2019, 600 questionnaires were distributed online in the study duration. Among 13 training bases, clinical teachers with over one year of teaching experience were approached for participation. Specifically, the recruitment provided a brief synopsis of the research aims and design and enrolled clinical teachers who were available, willing, and interested. Altogether, participants consisted of 574 senior faculty members who read and signed informed content and completed the survey independently, representing $95.7 \%$.

\section{Instruments}

The questionnaire was designed by reviewing much relevant literature and consulting relevant experts for modification. The selfadministered questionnaire had 19 items, respectively, which included three sections: (1) demographic information, (2) career information, and (3) perceived cognitive job satisfaction.

\section{Measurements}


Cognitive job satisfaction. The cognitive job satisfaction aimed to evaluate participants' cognitions about the job. ${ }^{22}$ The study divided satisfaction into positive attitude (PA) and negative attitude (NA), including ten items. The answers from participants were collected into "yes" and "no" for PA and NA, respectively. When evaluating teachers' satisfaction with the teaching subsidies and training base supplements, the original response options were "very satisfied," "satisfied," "a little satisfied," "dissatisfied," and "very dissatisfied." The five options were divided into "PA" ("very satisfied," "satisfied," and "a little satisfied") and "NA" ("dissatisfied" and "very dissatisfied").

Individual Covariates. Section 1 consisted of necessary socio-demographic information: gender, age, marital status (recoded into married and other [including unmarried, divorced, and widowed]), and education level (junior college or college, and postgraduate or above). The covariates about career information in Section 2 included working experience (10-year categories), professional titles (attending physician, deputy chief physician, and chief physician), hospital types (TCM hospital, specialized hospital, and general hospital), hospital levels (tertiary hospital, and non-tertiary hospital), and clinical departments (department of internal medicine, surgical department, and others).

\section{Statistical analyses}

The study calculated frequency, percentage, mean, and standard deviation (SD) to describe the demographic and career information. The study tested univariate analysis by applying the Chi-square test and Fisher's Exact test firstly. Significant variables ( $p$-value of $\leq 0.05)$ from the univariate analysis were subjected to multivariate analysis. Moreover, the study employed Logistic Regression Analysis to explore the association between the covariates and satisfactions. All statistical analyses were performed using SPSS18.0 software, and a variable with a p-value $\leq 0.05$ was considered statistically significant. The adjusted odds ratios (ORs) and their $95 \%$ confidence intervals (Cls) of independent variables were estimated.

\section{Institutional ethics exemption}

The study registered as an institutional ethics exemption, which involves the use of educational tests (cognitive, diagnostic, aptitude, or achievement tests). ${ }^{23,24}$ Considered minimizing the study's risks and to protect subjects' identities are protected, researchers provided informed content to all recruited participants and presented a brief description of the study before answering the questionnaires, including the purpose, time commitment, and any risks. All members of the research team completed the required online training module through the Collaborative Institutional Training Initiative (CITI) Program. ${ }^{23}$

\section{Results}

\section{Demographic and career information}

In this study, 530 (92.3\%) clinical teachers were under 50 years old. Around half of the participants were female (50.2\%), and $97.6 \%$ of the instructors were married or cohabited. Of the 574 participants, $76 \%$ of clinical teachers graduated from junior college or college. Four-fifths (79.1\%) of participants had been teaching for 1 10 years. Besides, two-thirds (66.4\%) of participants worked in general hospitals, and 228 (39.7\%) clinical teachers worked in tertiary hospitals. More than half $(59.8 \%)$ of the teachers had deputy chief physician or chief physician titles. Participants were recruited from different hospital departments $-67(11.7 \%)$ teachers in the internal medicine department, 204 (35.5\%) teachers work in the surgical department, and 52.8\% in other departments. 
Table 1

Demographic and Career-Related Characteristics for Participants $(n=574)$

\begin{tabular}{|c|c|c|}
\hline & $\mathbf{n}$ & $\%$ \\
\hline \multicolumn{3}{|l|}{ Sex } \\
\hline Male & 286 & 49.8 \\
\hline Female & 288 & 50.2 \\
\hline \multicolumn{3}{|l|}{ Marital status } \\
\hline Married or cohabited & 560 & 97.6 \\
\hline Others (i.e., unmarried, divorced\& widowed) & 14 & 2.4 \\
\hline \multicolumn{3}{|l|}{ Age (years) } \\
\hline$<=40$ & 297 & 51.7 \\
\hline $41 \sim 50$ & 233 & 40.6 \\
\hline $51 \sim 60$ & 44 & 7.7 \\
\hline \multicolumn{3}{|l|}{ Education } \\
\hline Junior college or college & 437 & 76.3 \\
\hline Postgraduate or above & 137 & 23.9 \\
\hline \multicolumn{3}{|l|}{ Title } \\
\hline Attending physician & 231 & 40.2 \\
\hline Deputy chief physician & 225 & 39.2 \\
\hline Chief physician & 118 & 20.6 \\
\hline \multicolumn{3}{|l|}{ Hospital level } \\
\hline Tertiary class & 228 & 39.7 \\
\hline Non- tertiary class & 346 & 60.3 \\
\hline \multicolumn{3}{|l|}{ Types of hospital } \\
\hline TCM hospital & 112 & 19.5 \\
\hline Specialized hospital & 81 & 14.1 \\
\hline General hospital & 381 & 66.4 \\
\hline \multicolumn{3}{|l|}{ Teaching experience (years) } \\
\hline $1-10$ & 454 & 79.1 \\
\hline $11-20$ & 96 & 16.7 \\
\hline $21-30$ & 22 & 3.8 \\
\hline \multicolumn{3}{|l|}{ Department } \\
\hline Internal medicine & 67 & 11.7 \\
\hline Surgery & 204 & 35.5 \\
\hline Others & 303 & 52.8 \\
\hline
\end{tabular}


The study evaluated the clinical teachers' satisfaction according to the PA and NA prevalence from ten items (shown in Table 2). Lots of the items received a higher percentage of PA. In detail, $86.9 \%$ of clinical teachers responded positively to the program design, and $86.4 \%$ thought the training and promotion design was reasonable. Almost all teachers $(96.3 \%)$ believed the provided contents met teaching requirements, and $94.6 \%$ of them evaluated the SRTP as helpful for students. Besides, $83.1 \%$ of teachers thought administrators had paid enough attention to training, and $60.8 \%$ of clinical teachers thought students were enthusiastic about studying in the SRTP. Also, $80.5 \%$ of teachers were satisfied with their subsidies. However, more than half of the clinical teachers $(54.7 \%)$ believed that students' wages were insufficient. Around half of the participants (47.4\%) felt the training period was too long. Nearly one-third (39.2\%) of teachers thought students had conflicts between study and work.

Table 2

पThe satisfaction of clinical teachers towards SRTP

\begin{tabular}{|c|c|c|}
\hline \multirow[t]{2}{*}{ Items } & \multicolumn{2}{|c|}{$\begin{array}{l}\text { Cognitive job } \\
\text { satisfaction }\end{array}$} \\
\hline & PA (\%) & NA (\%) \\
\hline $\begin{array}{l}\text { The SRTP provides enough supported content (e.g., number of diseases and cases) to meet teaching } \\
\text { requirements. }\end{array}$ & $\begin{array}{l}553 \\
(96.3)\end{array}$ & $21(3.7)$ \\
\hline The newly developed design of the SRTP is reasonable. & $\begin{array}{l}496 \\
(86.4)\end{array}$ & $78(13.6)$ \\
\hline There is no problem with personnel policy by the SRTP. & $\begin{array}{l}499 \\
(86.9)\end{array}$ & $75(13.1)$ \\
\hline The SRTP does not cause conflicts between residents' studies and work. & $\begin{array}{l}394 \\
(68.6)\end{array}$ & $\begin{array}{l}180 \\
(31.4)\end{array}$ \\
\hline Leaders of medical institutions attach great importance to SRTP. & $\begin{array}{l}477 \\
(83.1)\end{array}$ & $97(16.9)$ \\
\hline The SRTP helps improve residents' abilities. & $\begin{array}{l}543 \\
(94.6)\end{array}$ & $31(5.4)$ \\
\hline The required training period for residents is not too long in the SRTP. & $\begin{array}{l}302 \\
(52.6)\end{array}$ & $\begin{array}{l}272 \\
(47.4)\end{array}$ \\
\hline The residents have high motivations to attend daily training. & $\begin{array}{l}349 \\
(60.8)\end{array}$ & $\begin{array}{l}225 \\
(39.2)\end{array}$ \\
\hline The residents' wage is good enough provided by SRTP. & $\begin{array}{l}260 \\
(45.3)\end{array}$ & $\begin{array}{l}314 \\
(54.7)\end{array}$ \\
\hline Clinical teachers' subsidies supported by SRTP are good. & $\begin{array}{l}462 \\
(80.5)\end{array}$ & $\begin{array}{l}112 \\
(19.5)\end{array}$ \\
\hline
\end{tabular}

Note ${ }^{\text {a }}$ Cognitive job satisfaction: job satisfaction be measured in cognitive (evaluative).

\section{Factors affecting the teacher's cognitive job satisfaction}

As shown in Table 3, gender, marital status, and educational level significantly affected clinical teachers' satisfaction. Significant differences existed between male and female clinical teachers' satisfaction regarding teaching subsidies $(p=0.003)$, and when evaluating items of "There is no conflict between studies and work" $(\mathrm{p}=0.006)$ and "Leaders of medical institutions attach great importance to SRTP" ( $\mathrm{p}<0.001)$. According to the item "The SRTP does not cause conflicts between residents' studies and work," clinical teachers who were married or cohabited reported higher agreement $(p=0.044)$, and teachers who graduated from the junior college or college also reported the higher agreement $(p=0.003)$. 
Table 3

Univariate analysis of demographic and career variables clinical teachers' satisfaction $(\mathrm{N}=574)$

\begin{tabular}{|c|c|c|c|c|c|c|c|c|c|}
\hline Items & $\operatorname{Sex}^{c}$ & $\begin{array}{l}\text { Marital } \\
\text { Status }^{\mathrm{c}}\end{array}$ & Age & $\begin{array}{l}\text { Education } \\
\text { Levelc }^{c}\end{array}$ & Title $^{c}$ & $\begin{array}{l}\text { Hospital } \\
\text { Level }^{c}\end{array}$ & $\begin{array}{l}\text { Types of } \\
\text { Hospital }\end{array}$ & $\begin{array}{l}\text { Teaching } \\
\text { experiences }\end{array}$ & Department ${ }^{c}$ \\
\hline & & & & \multicolumn{6}{|c|}{ P-value $\left(x^{2}\right)^{a}$} \\
\hline $\begin{array}{l}\text { The SRTP } \\
\text { provides } \\
\text { enough } \\
\text { supported } \\
\text { content (e.g., } \\
\text { number of } \\
\text { diseases and } \\
\text { cases) to } \\
\text { meet } \\
\text { teaching } \\
\text { requirements. }\end{array}$ & $\begin{array}{l}0.811 \\
(0.057)\end{array}$ & $1.000^{\mathrm{b}}$ & $\begin{array}{l}0.619 \\
(0.958)\end{array}$ & $\begin{array}{l}0.995 \\
(<0.001)\end{array}$ & $\begin{array}{l}0.967 \\
(0.068)\end{array}$ & $\begin{array}{l}0.227 \\
(1.459)\end{array}$ & $\begin{array}{l}0.308 \\
(1.936)\end{array}$ & $\begin{array}{l}0.394 \\
(1.862)\end{array}$ & $\begin{array}{l}0.067 \\
(5.411)\end{array}$ \\
\hline \multirow{2}{*}{$\begin{array}{l}\text { The newly } \\
\text { developed } \\
\text { design of the } \\
\text { SRTP is } \\
\text { reasonable. }\end{array}$} & 0.135 & $0.109^{b}$ & 0.121 & 0.213 & 0.107 & 0.212 & 0.160 & 0.441 & 0.149 \\
\hline & $(2.234)$ & & $(4.231)$ & $(0.644)$ & $(4.463)$ & $(1.560)$ & (3.670) & $(1.639)$ & $(3.802)$ \\
\hline \multirow{2}{*}{$\begin{array}{l}\text { There is no } \\
\text { problem with } \\
\text { personnel } \\
\text { policy by the } \\
\text { SRTP. }^{\text {d }}\end{array}$} & 0.101 & $0.234^{\mathrm{b}}$ & 0.846 & 0.368 & 0.100 & $0.038 *$ & $0.005^{* *}$ & 0.980 & 0.573 \\
\hline & $(2.697)$ & & $(0.334)$ & $(0.811)$ & $(4.602)$ & (4.317) & (10.571) & $(0.041)$ & $(1.115)$ \\
\hline \multirow{2}{*}{$\begin{array}{l}\text { The SRTP } \\
\text { does not } \\
\text { cause } \\
\text { conflicts } \\
\text { between } \\
\text { residents' } \\
\text { studies and } \\
\text { work. }^{d}\end{array}$} & $0.006 * *$ & $0.044^{\star b}$ & 0.981 & $0.003^{* *}$ & 0.135 & 0.408 & $0.025^{*}$ & 0.421 & $0.046 *$ \\
\hline & (7.592) & & $(0.039)$ & (8.778) & $(4.012)$ & $(0.685)$ & (7.392) & $(1.730)$ & $(6.177)$ \\
\hline \multirow{2}{*}{$\begin{array}{l}\text { Leaders of } \\
\text { medical } \\
\text { institutions } \\
\text { attach great } \\
\text { importance } \\
\text { to SRTP. }\end{array}$} & $<0.001 * \star \star$ & $1.000^{\mathrm{b}}$ & 0.304 & 0.763 & 0.117 & $0.009 * *$ & $0.017 *$ & 0.120 & 0.131 \\
\hline & (12.183) & & $(2.385)$ & $(0.091)$ & $(4.296)$ & $(6.817)$ & (8.139) & $(4.245)$ & $(4.070)$ \\
\hline \multirow{2}{*}{$\begin{array}{l}\text { The SRTP } \\
\text { helps } \\
\text { improve } \\
\text { residents' } \\
\text { abilities. }\end{array}$} & 0.869 & $0.545^{\mathrm{b}}$ & 0.249 & 0.863 & 0.245 & 0.383 & 0.848 & 0.670 & 0.933 \\
\hline & $(0.027)$ & & (2.777) & $(0.030)$ & (2.817) & $(0.762)$ & $(0.330)$ & $(0.800)$ & $(0.138)$ \\
\hline \multirow{2}{*}{$\begin{array}{l}\text { The required } \\
\text { training } \\
\text { period for } \\
\text { residents is } \\
\text { not too long } \\
\text { in the SRTP. }\end{array}$} & 0.360 & 0.459 & 0.099 & 0.246 & 0.148 & $0.017 *$ & $0.019 *$ & 0.547 & 0.562 \\
\hline & $(0.838)$ & $(0.548)$ & $(4.624)$ & $(1.348)$ & (3.819) & $(5.686)$ & (7.875) & $(1.208)$ & $(1.152)$ \\
\hline
\end{tabular}

Note. ${ }^{a}$ Values were calculated from Chi-Square Test to examine effects from demographical information and career characteristic on the clinical teachers' satisfactions (significant at ${ }^{\star} p \leq 0.05 ;{ }^{* \star} p \leq 0.01 ;{ }^{* \star \star} p \leq 0.001$ ).

${ }^{b}$ Values were calculated from Fisher- Exact Test to examine effects from demographical information and career characteristic on the clinical teachers' satisfactions (significant at * $\mathrm{k} \leq 0.05 ;{ }^{* \star} \mathrm{p} \leq 0.01 ;{ }^{\star \star \star} \mathrm{p} \leq 0.001$ ).

c Significant variables were calculated into the model when subsequent multivariable analyses.

d Questionnaire items, which have significant factors from univariate analysis, can build the logistical model 


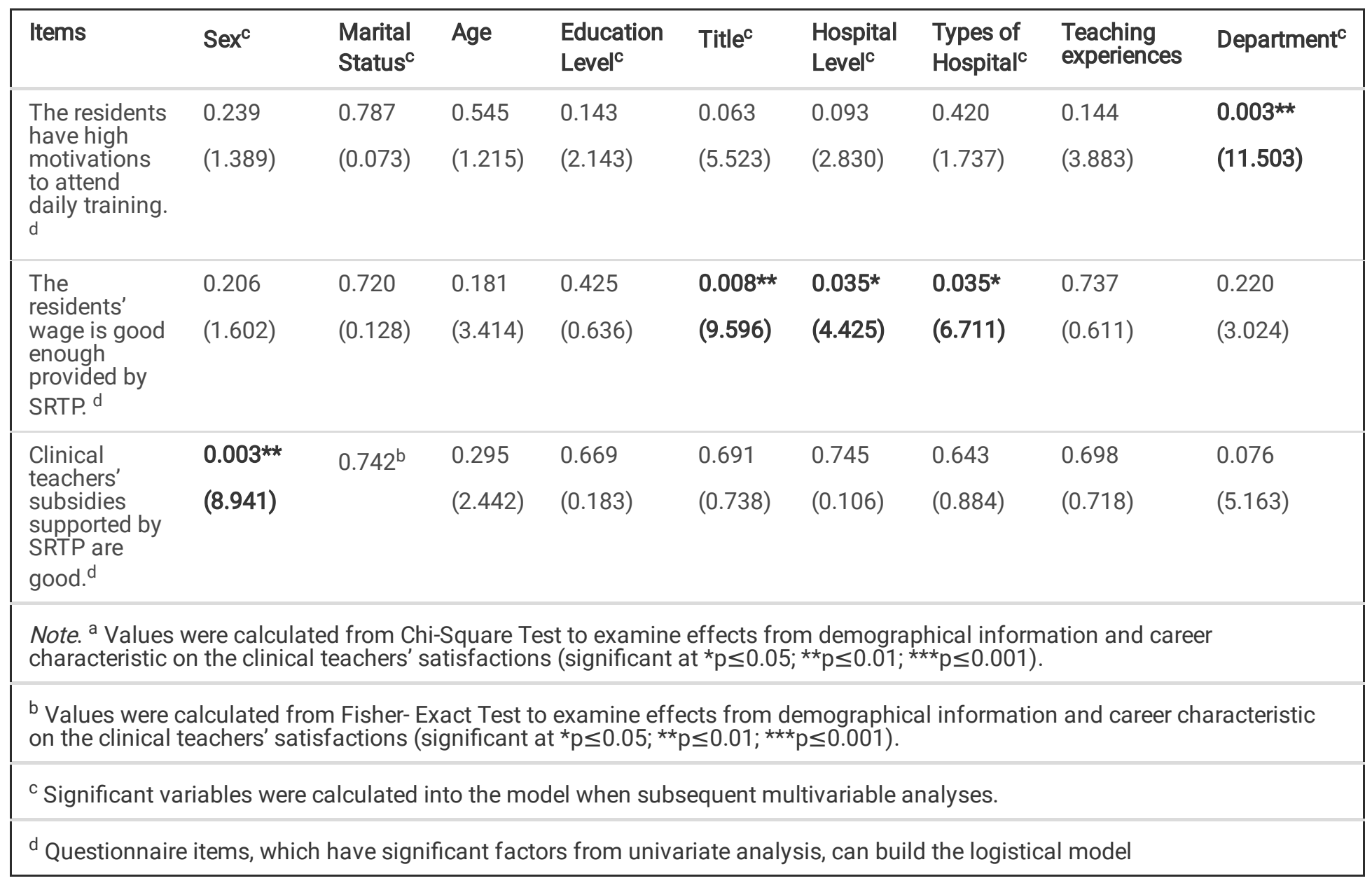

Furthermore, titles, hospital levels, and working department types were significantly associated with teachers' satisfaction. Specifically, titles affected teachers' satisfaction with students' wages $(p=0.008)$. Among different hospital levels, the significant differences of teachers' recognition were calculated from 4 items: "The SRTP does not cause conflicts between residents' studies and work" ( $\mathrm{p}=0.038)$; "Leaders of medical institutions attach great importance to SRTP" $(\mathrm{p}=0.009)$; "The required training period for residents is not too long in the SRTP' ( $\mathrm{p}=0.017)$; "The residents' wage is good enough provided by SRTP" $(\mathrm{p}=0.035)$. There had significant differences among teachers in different hospital types regarding whether training was too long $(p=0.020)$, whether there was no problem with the training and promotion design $(p=0.005)$, whether there was a conflict between study and work $(p=0.025)$, and whether students' payments were good enough $(p=0.035)$. Also, different working departments influenced teachers' satisfaction about whether there were conflicts between study and work $(p=0.046)$ and whether students were highly motivated $(p=0.003)$.

Univariate analysis of all variables was detailed in Supplementary File 1.

\section{Logistic regression analysis of teachers' cognitive job satisfaction}

In univariate analysis, variables with statistical significance to clinical teachers' satisfaction among demographic and career variables were obtained and applied in the logistic regression model. The logistic regression analysis showed that variables of gender, marital status, types of hospital, title, and working departments influenced clinical teachers' satisfaction significantly.

Notably, male (OR: 0.542, [95\%Cl: 0.371- 0.791]), graduated as postgraduate or above (OR: 0.612, [95\% Cl: 0.404-0.926]), unmarried, divorced\& widowed (OR: 0.280, [95\% Cl:0.093- 0.849]), and TCM hospitals' teachers (OR: 0.466, [95\% Cl: 0.294- 0.739]) were more dissatisfied with "The SRTP does not cause conflicts between residents' studies and work'. Male teachers (OR: 0.403, [95\%Cl: 0.2520.645] reported lower agreement with "Leaders of medical institutions attach great importance to SRTP." Besides, male clinical teachers (OR: 0.527, [95\% Cl: 0.347- 0.805]) were less satisfied with teachers' subsidies. Compared with the department of internal medicine, clinical teachers from the department of surgery (OR: 2.396, [95\% Cl: 1.365- 4.206]) and other departments (OR: 2.409, [95\%Cl: 1.406- 4.129]) were more satisfied when considered "The residents have high motivations to attend daily training." Further, compared with attending physician, deputy chief physician (OR: $0.493,[95 \% \mathrm{Cl}: 0.310-0.783])$ and chief physician (OR: $0.683,[95 \% \mathrm{Cl}$ : 0.471- 0.991]) more disagreed that student's wage is good enough. (Shown in Table 4). 
Page 9/16 
Table 4

Logistic regression analysis of teachers' satisfaction

\begin{tabular}{|c|c|c|c|c|}
\hline Model & Characteristic & & OR $(95 \% \mathrm{Cl})$ & $\begin{array}{l}P \\
\text { value }\end{array}$ \\
\hline \multirow{5}{*}{$\begin{array}{l}\text { There is no problem with personnel policy by the } \\
\text { SRTP. }\end{array}$} & Hospital level & Tertiary class & Reference & \\
\hline & & Non- tertiary class & $\begin{array}{l}1.392(0.548- \\
3.539)\end{array}$ & .487 \\
\hline & $\begin{array}{l}\text { Types of } \\
\text { hospital }\end{array}$ & General hospital & Reference & \\
\hline & & TCM hospital & $\begin{array}{l}0.575(0.218- \\
1.522)\end{array}$ & .256 \\
\hline & & Specialized hospital & $\begin{array}{l}1.512(0.486- \\
4.704)\end{array}$ & .476 \\
\hline \multirow{12}{*}{$\begin{array}{l}\text { The SRTP does not cause conflicts between } \\
\text { residents' study and work. }\end{array}$} & Gender & Female & Reference & \\
\hline & & Male & $\begin{array}{l}0.568(0.391- \\
0.826)\end{array}$ & .003 \\
\hline & $\begin{array}{l}\text { Marital } \\
\text { status }\end{array}$ & $\begin{array}{l}\text { Recorded married or } \\
\text { cohabited }\end{array}$ & Reference & \\
\hline & & $\begin{array}{l}\text { Others (i.e. unmarried, } \\
\text { divorced\& widowed) }\end{array}$ & $\begin{array}{l}0.276(0.091- \\
0.837)\end{array}$ & .023 \\
\hline & Education & Junior college or college & Reference & \\
\hline & & Postgraduate or above & $\begin{array}{l}0.612(0.404- \\
0.926)\end{array}$ & .020 \\
\hline & $\begin{array}{l}\text { Types of } \\
\text { hospital }\end{array}$ & General hospital & Reference & \\
\hline & & TCM hospital & $\begin{array}{l}0.514(0.327- \\
0.807)\end{array}$ & .004 \\
\hline & & Specialized hospital & $\begin{array}{l}1.053(0.596- \\
1.863)\end{array}$ & .858 \\
\hline & Department & Internal medicine & Reference & \\
\hline & & Surgery & $\begin{array}{l}1.482(0.823- \\
2.668)\end{array}$ & .190 \\
\hline & & Others & $\begin{array}{l}1.692(0.962- \\
2.975)\end{array}$ & .068 \\
\hline \multirow{7}{*}{$\begin{array}{l}\text { Leaders of medical institutions attach great } \\
\text { importance to SRTP. }\end{array}$} & Gender & Female & Reference & \\
\hline & & Male & $\begin{array}{l}0.403(0.252- \\
0.645)\end{array}$ & $<0.001$ \\
\hline & Hospital level & Tertiary class & Reference & \\
\hline & & Non- tertiary class & $\begin{array}{l}1.828(0.810- \\
4.126)\end{array}$ & .147 \\
\hline & $\begin{array}{l}\text { Types of } \\
\text { hospital }\end{array}$ & General hospital & Reference & \\
\hline & & TCM hospital & $\begin{array}{l}0.700(0.294- \\
1.668)\end{array}$ & .421 \\
\hline & & Specialized hospital & $\begin{array}{l}1.538(0.586- \\
4.038)\end{array}$ & .382 \\
\hline $\begin{array}{l}\text { The required training period for residents is not too } \\
\text { long in the SRTP. }\end{array}$ & Hospital level & Tertiary class & Reference & \\
\hline
\end{tabular}




\begin{tabular}{|c|c|c|c|c|}
\hline \multirow[t]{5}{*}{ Model } & \multicolumn{2}{|l|}{ Characteristic } & \multirow{2}{*}{$\begin{array}{l}\text { OR (95\%Cl) } \\
\begin{array}{l}1.024(0.536- \\
1.958)\end{array}\end{array}$} & \multirow{2}{*}{$\begin{array}{l}\mathbf{P} \\
\text { value } \\
.943\end{array}$} \\
\hline & & Non- tertiary class & & \\
\hline & $\begin{array}{l}\text { Types of } \\
\text { hospital }\end{array}$ & General hospital & Reference & \\
\hline & & TCM hospital & $\begin{array}{l}0.585(0.287- \\
1.193)\end{array}$ & .140 \\
\hline & & Specialized hospital & $\begin{array}{l}0.689(0.326- \\
1.459)\end{array}$ & .331 \\
\hline \multirow{3}{*}{$\begin{array}{l}\text { The residents have high motivations to attend } \\
\text { daily training. }\end{array}$} & Department & Internal medicine & Reference & \\
\hline & & Surgery & $\begin{array}{l}2.396(1.365- \\
4.206)\end{array}$ & .002 \\
\hline & & Others & $\begin{array}{l}2.409(1.406- \\
4.129)\end{array}$ & .001 \\
\hline \multirow{8}{*}{$\begin{array}{l}\text { The residents' wage is good enough provided by } \\
\text { SRTP. }\end{array}$} & Title & Attending physician & Reference & \\
\hline & & Deputy chief physician & $\begin{array}{l}0.493(0.310- \\
0.783)\end{array}$ & .003 \\
\hline & & Chief physician & $\begin{array}{l}0.683(0.471- \\
0.991)\end{array}$ & .045 \\
\hline & Hospital level & Tertiary class & Reference & \\
\hline & & Non- tertiary class & $\begin{array}{l}0.939(0.490- \\
1.799)\end{array}$ & .850 \\
\hline & $\begin{array}{l}\text { Types of } \\
\text { hospital }\end{array}$ & General hospital & Reference & \\
\hline & & TCM hospital & $\begin{array}{l}0.542(0.263- \\
1.115)\end{array}$ & .096 \\
\hline & & Specialized hospital & $\begin{array}{l}0.687(0.322- \\
1.470)\end{array}$ & .334 \\
\hline \multirow{2}{*}{$\begin{array}{l}\text { Clinical teachers' subsidies supported by SRTP are } \\
\text { good. }\end{array}$} & Gender & Female & Reference & \\
\hline & & Male & $\begin{array}{l}0.527(0.347- \\
0.805)\end{array}$ & .003 \\
\hline
\end{tabular}

\section{Discussion}

Most clinical teachers hold a positive attitude and have widely accepted the SRTP based on their evaluation of each item. However, teachers with different personality traits present different opinions after exploring the items in detail. The main findings indicated that most teachers with different genders, working departments, and professional titles have significant differences in satisfaction levels. While only evaluating the clinical teachers' overall satisfaction is inaccurate to find issues of SRTP, ${ }^{25}$ the possible influential factors and caused reasons combined Chinese society characteristics might provide valued recommendations to develop SRTP in the future.

Initially, the results reported that the male clinical teachers' evaluations were low because of the unsatisfactory teaching content and caused conflicts between students' study and work. Also, comparing with the female counterparts, more male teachers evaluated the SRTP receive little attention from the leaders, and the provided subsidies to teachers are not good. Undoubtedly, job satisfaction is a function of individual differences, and some studies discussed that males and females relied on different cognitive-emotional regulation strategies, receiving different satisfaction degrees. ${ }^{26-29}$ For example, American women reported more meditation, 
catastrophizing, refocusing actively, ${ }^{27}$ refocusing on planning, and positive reappraisal. In contrast, American men scored higher in blaming others. Chinese culture's gendered social role expectations are another reason. ${ }^{20,30}$

The cultural traditions and religious convictions shaped men's role, who receives society expected to be the chief breadwinner and responsible for supporting their families. ${ }^{31,32}$ On the contrary, the traditional community assumes women to do household work such as child-rearing and day-to-day life chores. Although some evidence stated that promoting gender equality of working already improved women's status, the traditional gender roles still appeared pervasively. Chinese female employees experienced more conflicts from their roles at home and the workplace. Because of the contradictory expectations from gender roles, men and women evaluated job satisfaction with different factors. ${ }^{30}$ We believed that it was the primary explanation for the lower satisfaction of the male. According to the previous findings, male considered main determinants include income, responsibility, and professional development opportunities. In contrast, women considered job stability, the balance between work and family, and the professional status more critically. Also, some studies reported that Chinese men attached higher importance to challenging work and valued professional development opportunities than their female counterparts. ${ }^{27}$ Recent research examined the incentives to help improve clinical teachers' motivation; it found that educators were highly motivated when they felt their leaders value the work of teaching. ${ }^{33}$ Therefore, the study recommended that SRTP manage and spread diverse work types with different gender. Also, the management in the SRTP can develop more reward policies to increase the incentive mechanism and then improve clinical teachers' sense of responsibility and honor. ${ }^{17}$

The results also indicated that most clinical teachers believe that the residents' enthusiasm for studying in the SRTP is high. However, compared with the Surgery and other departments' clinical teachers, the clinical teachers who worked as the internal medicine physicians were less satisfied when considered "The residents have high motivations to attend daily training." Almost all internal medicine departments work on geriatric chronic diseases and severe and complicated cases in China. The current situation leads the typical patients with milder conditions to be few, which causes clinical teachers to apply related diseases that cover differential diagnoses and treatments as teaching cases. ${ }^{34,35}$ However, the training period of the above studies are limited to residents. During the entire 33 months, residents must attend 29 months of rotation training in the various subspecialties (Cardiology, Nephrology, Gastroenterology, etc.) and 4 months of rotation training in the elective subjects under the internal medicine department. ${ }^{7,10,36}$. Except to participate in outpatient and emergency work and various teaching activities (teaching visits, case discussions, professional lectures, etc.), residents also have to complete the required number of diseases and basic skills. In short, excessive concentration of learning during the short-term rotation period burdens residents' pressure to make their residency training more challenging.

Communication between residents and patients during outpatient training may be another reason. Many internal medicine patients have to suffer long-term illnesses and repeated hospitalization. ${ }^{36,37}$ Thus, their minds and emotion are the most depressed. A previous study stated that many patients resent residents; they are reluctant to accept residents' consultation, body investigation and diagnosis, and treatment operations. That might be a barrier to affect the residents' studying to a certain extent. ${ }^{37}$ Therefore, the study recommended that the SRTP strengthened communication with patients to obtain their cooperation and chose typical cases that were relatively mild and easy to communicate. Specifically, all clinical teachers can select patients to be involved in the clinical practice teaching. What is more, the educators can communicate with the patients before the class to explain the time, purpose, and time of teaching, obtaining the patients' and their families' understanding.

At least, the deputy chief physician and chief physician disagreed that students' wages are good enough compared with the attending physician. The caused reason may be that different professionals' roles are played in providing teaching quality in the SRTP. As the mild-level title, attending physicians are the main forces of clinical care in Chinese hospitals. However, most of them who work in the inpatient setting remain at this stage for the better part of their careers due to the vice chief physician requirements. ${ }^{38}$ Under the system with high competitiveness, the contribution work to develop SRTP is an opportunity to attending physicians. Until now, many SRTP training bases already applied rewarding and punishing policies to evaluate teachers' performance, includes the number of teaching residents and the passing rate of the complete assessment. Most importantly, these results are often related to the reputation of the teachers, such as promotion, salary increase, evaluation, and dismissal. ${ }^{36-41}$ Therefore, the final purpose of attending physicians to provide training in the SRTP is to earn rewards to be promoted as deputy chief physicians. 
For many deputy and chief physicians, the promotion no longer has an incentive effect on them. Instead, broadening the academic field, mastering cutting-edge theories and methods, and seeking medical talents have become their potential needs. Also, many hospitals with SRTP maintain the appropriate proportion of chief physicians to deputy chief physicians to attending physicians to residents at the ratio of 1:2:4:8. ${ }^{38}$ Under this distribution, except supervising interns and residents as an instructor in the SRTPs, the deputy chief and chief physicians also needed to act as administrative leaders in clinical departments. They are more concerned about residents' situations, besides their income. The study recommended that leaders incorporate resident physicians' performance appraisal as a reference basis for salary distribution and give resident physicians certain material rewards with excellent daily routines. ${ }^{42,44}$

\section{Study Limitations}

Several limitations of this study still occurred and should be addressed in the future. Firstly, this study used a simple random sampling design to recruit clinical teachers within a single city in Zhejiang province. Thus, considering the bias from different regions, adding more areas in the future study to verify the current findings can be applied and interpreted nationwide. Secondly, the questionnaire in this study was self-designed. Although the literature research and the interviews with the first-lined managers of SRTP supported the primary evidence of the content validity of the scale items, the scale development and measurement of relevant concepts should be improved for further study. Furthermore, future research might take more contextual factors and curriculum planning in different clinical settings into consideration. ${ }^{34,35,38,43}$

\section{Conclusion}

In summary, the broad implication of the present research leads to the following conclusions: the gender difference between the clinical teachers induced different satisfactions; the clinical teachers who worked in various departments presented different evaluations to the SRTP; the working titles of the clinical teachers also influenced their satisfaction with the SRTP. Therefore, several suggested strategies were provided: to increase the incentive mechanism to improve the sense of responsibility and honor of clinical teachers, enforce the education about communications between residents and patients, and provide more welfares to solve the issue of low payments to residents.

\section{Abbreviations}

SRTP: Standardized Residency Training Program

NHFPC: National Health and Family Planning Commission

NMEC: National Medical Examination Center

PA: Positive attitude

NA: Negative attitude

CITI: Collaborative Institutional Training Initiative Program

\section{Declarations}

\section{Acknowledgments}

The authors thank all participants in the 13 residency standardization bases in Shaoxing, all the team members. The authors also thank Zhiying Jin from the Continuing Education Center in Shaoxing and Yueping Zhu from Shaoxing University Affiliated Hospital for their generous support.

\section{Authors' contributions}

$B Y C, X Y J, J Z, Y C$, and HMW contributed the idea for the review. HMW and BYC designed the study. BYC, XYJ, JZ, and HMW were conducted to write the manuscript. BYC, XYJ, and JZ contributed equally to writing to this study. YC, BYC, and HMW collected

Page $13 / 16$ 
primary data, analyzed results, and designed exhibits. XYJ and HMW contributed to the critical review of the manuscript. All authors reviewed and approved the final version.

\section{Funding}

The study was developed without funding supports. There are no financial conflicts of interest to disclose.

\section{Availability of data and materials}

The online survey collected all data used via using Wenjuanxing Platform. (https://www.wjx.cn/app/survey.aspx). More detailed data used and/or analyzed during the current study are available from the corresponding author on reasonable request.

\section{Ethics approval and consent to participate}

Since involving the use of educational tests (cognitive, diagnostic, aptitude, or achievement tests), this study was registered as an institutional ethics exemption and was waived the need for ethic approval by the Zhejiang Medical Ethics Committee (https://lunli.wsjkw.zj.gov.cn/). Goal to minimize the study's risks and protect subjects' identities, the study provided informed content to all recruited participants and presented a brief description of the study, including the purpose, time commitment, and any risks. All participants involved in the study analysis have read and signed the informed context before starting the survey. All research team members completed the required online training module through the Collaborative Institutional Training Initiative (CITI Program). Data were linked and analyzed only by authors who contributed to writing the article.

\section{Consent for publication}

Not applicable.

\section{Competing interests}

The authors declare that they have no competing interests. The authors are responsible for the content and writing of the article. All authors contributed to the critical revision of the manuscript. All approved the final manuscript for submission and have agreed to be accountable for the accuracy and integrity of the work.

\section{References}

1. Seely AJ, Pelletier MP, Snell LS, Trudel JL. Do surgical residents rated as better teachers perform better on in-training examinations?. American journal of surgery. 1999; 177(1), 33-37. https://doi.org/10.1016/s0002-9610(98)00306-7

2. Lian S, Xia Y, Zhang J, Han X, Chi C, Fetters M. Comparison of general practice residents' attitudes and perceptions about training in two programmes in China: a mixed methods survey. Family Medicine And Community Health. 2019; 7(4), e000238. doi: 10.1136/fmch-2019-000238

3. Bulte C, Betts A, Garner K, Durning S. Student teaching: views of student near-peer teachers and learners. Medical teacher. 2007; 29(6), 583-590.

4. Cueto J, Jr Burch VC, Adnan NA, Afolabi BB, Ismail Z, Jafri W, Olapade- Olaopa EO, Otieno-Nyunya B, Supe A, Togoo A, Vargas AL, Wasserman E, Morahan PS, Burdick W, Gary N. Accreditation of undergraduate medical training programs: practices in nine developing countries as compared with the United States. Education for health (Abingdon, England). 2006; 19(2), $207-222$.

5. Wang Yuan-yuan, Wang Rong-ying*, Zhang Jin-jia, Zhang Ya-li, Wang Ya-yi, Sun Yan-jie, Wang Jin-yan. Satisfaction of Trainees with the Standardized General Practitioner Training Delivered by the General Practice Department of a General Hospital. Chinese General Practice. 2018; 21(13): 1598-1602.

6. De Andrade F, Griebenow R, Costello RW, Guenova M, Schaefer R, Chalmers JD, Tichelli A, Raguz D, Stein J. The future of accreditation of continuing medical education (CME)-continuing professional development (CPD) in Europe: harmonisation through dialogue and consensus. Journal of European CME. 2018; 7(1). https://doi.org/10.1080/21614083.2018.1506202

7. National Health and Family Planning Commission. Guidance of the National Health and Family Planning Commission and seven other departments on the establishment of a standardized residency training system. Accessed in 2014. http://www.nhfpc.gov.cn/qjjys/s3593/201401/032c8cdf2eb64a369cca4f9b76e8b059.shtml 
8. National Health and Family Planning of the People's Republic of China. A report on the development of standardized residency training in China. Accessed in 2015.

http://www.nhfpc.gov.cn/qjjys/s3594/201505/953d3206bb1c4c869944e0a139328a0d.shtml

9. National Health Commission of the People's Republic of China. Letter of Response to Proposal No. 0868 (Medical Sports No. 089) of the Second Session of the 13th National Committee of the Chinese People's Political Consultative Conference. Accessed in 2020. http://www.nhc.gov.cn/wjw/tia/202009/4ea9a46a93374e23916eea36e52d1027.shtml

10. Department of Science, Technology and Education. Residency training has a national standard. Accessed in 2014.

11. Fang H, Wei L, Mao J, Jia H, Li P, Li Y. et al. Extent and risk factors of psychological violence towards physicians and Standardised Residency Training physicians: a Northern China experience. Health And Quality Of Life Outcomes. 2020; 18(1). doi: 10.1186/s12955-020-01574-y

12. Zhang $Y$, Huang $X$, Li H, Zeng $X$, Shen T. Survey results of job status of residents in a standardized residency training program. BMC Medical Education. 2019; 19(1). doi: 10.1186/s12909-019-1718-4

13. Huynh A, Savitski J, Kirven M, Godwin J, Gil K. Effect of Medical Students' Experiences With Residents as Teachers on Clerkship Assessment. Journal Of Graduate Medical Education. 2011; 3(3), 345-349. doi: 10.4300/jgme-03-03-35

14. Frey-Vogel A. A Resident-as-Teacher Curriculum for Senior Residents Leading Morning Report: A Learner-Centered Approach Through Targeted Faculty Mentoring. Mededportal. 2020; 16(1), 10954. doi: 10.15766/mep_2374-8265.10954

15. Tang CX, Tang DS. The trend and features of physician workforce supply in China: after national medical licensing system reform. Human Resources for Health. 2018; 16:18. https://doi.org/10.1186/s12960-018-0278-8

16. Wu L, Qi H, Wu J, Li J. Analysis on different general practitioner training mode effect. Chinese Journal Of Health Education. 2013; (5), 428-430, 440.

17. Wang J, Song M, Gao P, Gu Z, Jia M, Yao S et al. Survey of residency capability enhancement following standardized training. Chinese Journal Of Hospital Administration. 2015; 31(12), 905-909.

18. Chen L, Wang L, Ni W. Satisfaction analysis and policy recommendations of standardized training of specialist doctors in Shanghai Jiaotong University School of Medicine. Continuing Medical Education. 2016; 30(12), 1-3.

19. Geary A, Hess DT, Pernar L. Resident-as-teacher programs in general

20. surgery residency- A review of published curricula. American journal of

21. surgery. 2019; 217(2), 209-213. https://doi.org/10.1016/j.amjsurg.2018.09.003

22. Huang L, Hu S, Wang H, Cui H, Jin L. Study on the relation of job burnout and turnover intention in the resident physician of general standardized training program. Shanghai Medical \& Pharmaceutical Journal. 2017; 38(24), 7-11.

23. Musunuru S, Lewis B, Rikkers L, Chen H. Effective Surgical Residents Strongly Influence Medical Students to Pursue Surgical Careers. Journal Of The American College Of Surgeons. 2007; 204(1), 164-167. doi: 10.1016/j.jamcollsurg.2006.08.029

24. Organ D, Near J. Cognition vs Affect in Measures of Job Satisfaction. International Journal Of Psychology. 1985; 20(2), 241253. doi:10.1080/00207598508247735

25. Office for Human Research Protection (OHRP), 45 CFR 46, Office for Human Research Protections, Last reviewed March 10, 2021. https://www.hhs.gov/ohrp/regulations-and-policy/regulations/45-cfr-46/index.html

26. Zhejiang Medical Ethics Network: https://lunli.wsjkw.zj.gov.cn/interIndex.do?method=draftinfo\&draftld=2c91d463-71c9d3580171-c9d358b5-0000, Published on April 30, 2020.

27. Kafetsios K, Anagnostopoulos F, Lempesis E, Valindra A. Doctors' Emotion Regulation and Patient Satisfaction: A SocialFunctional Perspective. Health Communication. 2013; 29(2), 205-214. doi: 10.1080/10410236.2012.738150

28. Nelis D, Quoidbach J, Hansenne M, Mikolajczak M. Measuring Individual Differences in Emotion Regulation: The Emotion Regulation Profile-Revised (ERPR). Psychologica Belgica. 2011; 51(1), 49. doi: 10.5334/pb-51-1-49

29. Nie L. Gender Differences in Work Values in China. 2012; Master of Science (MS). Applied Sociology, Clemson University.

30. Glas $\emptyset$ L, Einarsen S. Emotion regulation in leader-follower relationships. European Journal Of Work And Organizational Psychology. 2008; 17(4), 482-500. doi: 10.1080/13594320801994960

31. Martin R \& Dahlen E. Cognitive emotion regulation in the prediction of depression, anxiety, stress, and anger. Personality And Individual Differences. 2005; 39(7),

Page 15/16 
32. -1260. doi: 10.1016/j.paid.2005.06.004

33. Jin Y, Schläger (eds.) C, Shen Y, Tan S, Wang B. Family Changes in China and Comparative Research of Family Policies (1st ed., pp. 134-141). Shanghai: Friedrich-Ebert-Stiftung (FES) China. Accessed in 2014.

34. Han X. Income Inequalities within Couples in China. Online First Statistical Research. 2012; 29(10), 79-84.

35. Qing S. Social-Cultural Roots of Gender Income Difference in China: Evidence from the Gender Role Attitudes. Online First Sociological Studies. 2019; 34(01), 106-131, 244. doi: 10.19934/j.cnki.shxyj.2019.01.005.

36. Wisener K, Driessen E, Cuncic C, Hesse C, Eva K. Incentives for clinical teachers: On why their complex influences should lead us to proceed with caution. Medical Education. 2020; 55(5), 614-624. doi: 10.1111/medu.14422

37. Esteghamati A, Baradaran H, Monajemi A, Khankeh HR, Geranmayeh M. Core components of clinical education: a qualitative study with attending physicians and their residents. Journal of advances in medical education \& professionalism. 2016; 4(2), 64-71.

38. Kelekar A, Afonso N. Evaluation of the effect of a new clinical reasoning curriculum in a pre-clerkship clinical skills course. Perspectives On Medical Education. 2020; 9(2), 123-127. doi: 10.1007/s40037-020-00566-4

39. Lio J, Ye Y, Dong H, Reddy S, McConville J, Sherer R. Standardized residency training in China: the new internal medicine curriculum. Perspectives On Medical Education. 2017; 7(1), 50-53. doi: 10.1007/s40037-017-0378-5

40. Science T, Division E. Notice of the office of the National Health and Family Planning Commission of issuing standardized residency training base standards and standardized residency training content and standards. Accessed in 2016.

41. http://

42. Leonard R. Working Lives of Chinese Physicians. Accessed in 2010. Retrieved from

43. https://repository.upenn.edu/uhf_2010/11

44. Dornan T, Roy BS, Kelly M. Medical teachers' discursive positioning of doctors in relation to patients. Medical Education. 2020; 54(7), 628-636. doi:10.1111/medu.14074.

45. Li X, Lin Z. Transformational, Transactional Leadership and Leadership Effectiveness: The Mediating Effects of Leader-member Exchange. Journal Of Chongqing University (Social Science Edition). 2013; 19(6), 56-64.

46. Zhang P, Tao H, Sun Y. A logical analysis of the reform of physicians' compensation system in public hospitals in China: A case study of Sanming City, Fujian Province. Chinese Journal Of Health Policy. 2017; (12), 33-37.

47. Liu C, Ouyang W, Wu J. A Survey on the Satisfaction of Standardized Residency Training in Chongqing. Open Journal Of Social Sciences. 2020; 08(02), 39-50. doi: 10.4236/jss.2020.82004.

48. Ark T, Brooks L, Eva K. Giving Learners the Best of Both Worlds: Do Clinical Teachers Need to Guard Against Teaching Pattern Recognition to Novices?. Academic Medicine. 2006; 81(4), 405-409. doi: 10.1097/00001888-20060400000017.

49. Wu J, Li J, Wang G. Questionnaire survey and needs analysis of the professional degree education in residency standardized training. Chinese Journal Of Medical Education. 2014; 34(2), 285-287.

\section{Supplementary Files}

This is a list of supplementary files associated with this preprint. Click to download.

- SupplementaryFile1Univariateanalysisincludeallvariablescomplectedversion.docx

- SupplementaryFile2DeclarationofIRBExemption.docx 